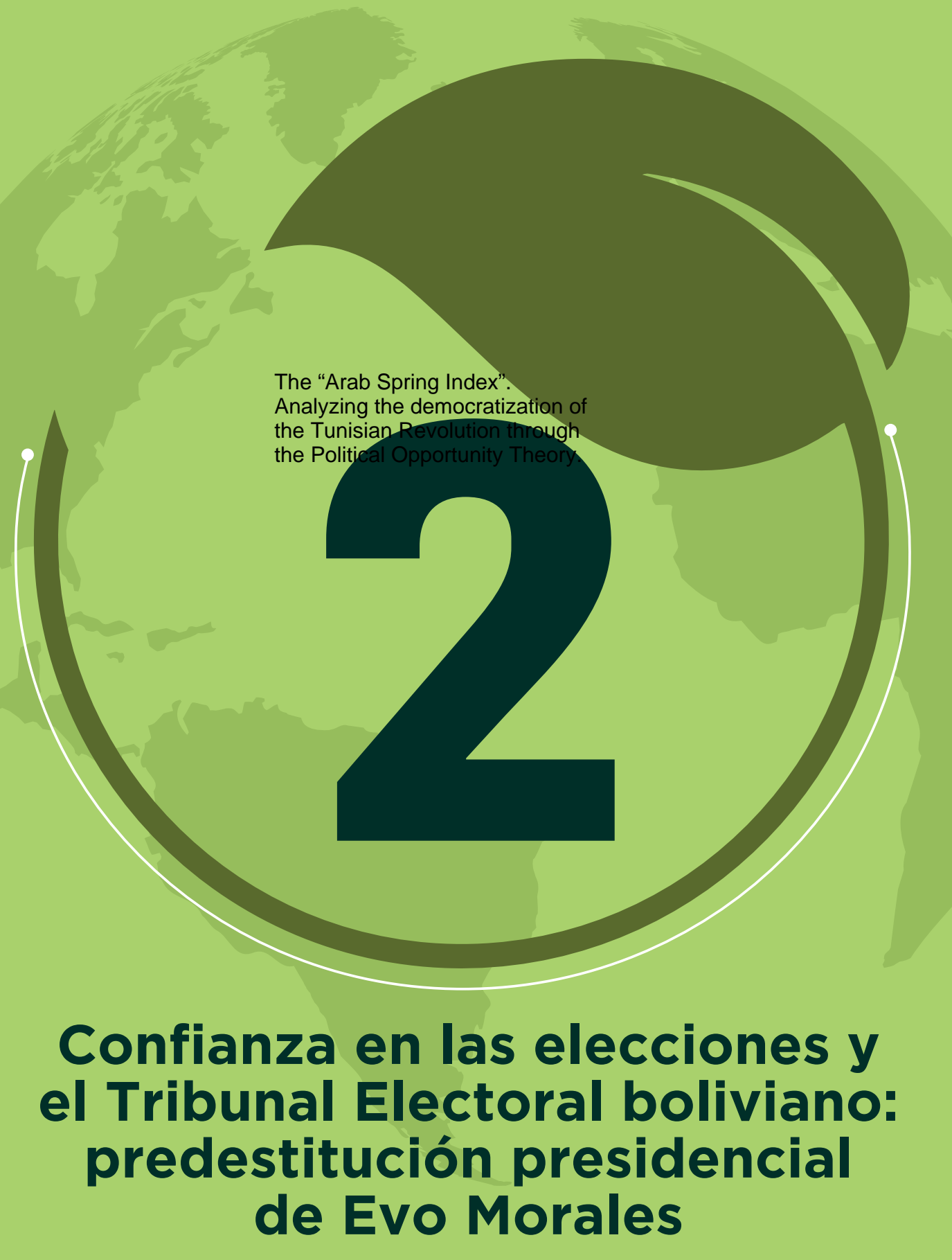



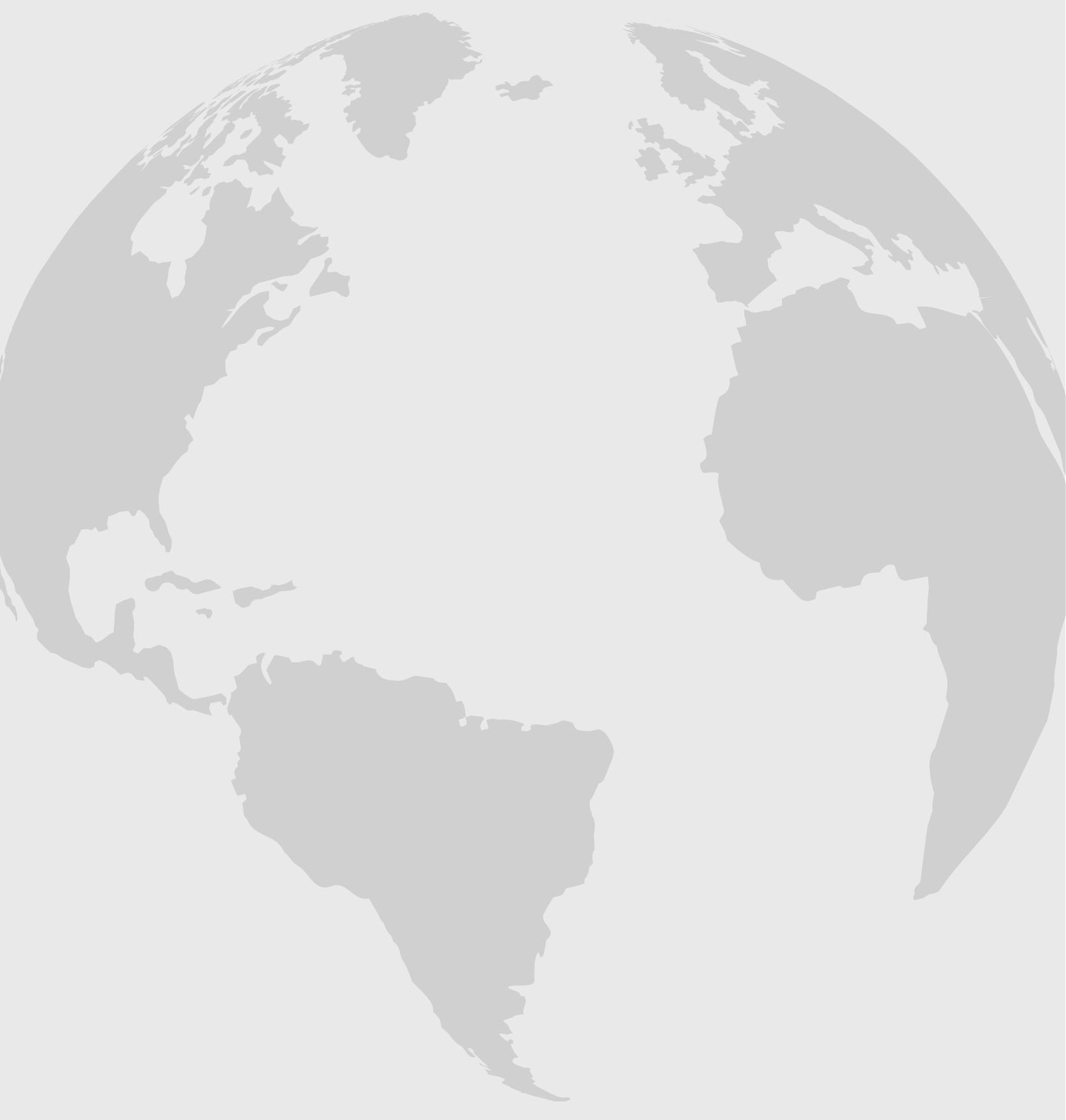


\section{Confianza en las elecciones y el Tribunal Electoral boliviano: predestitución presidencial de Evo Morales}

Ana María Llumiquinga Vilatuña,

Facultad Latinoamericana de Ciencias Sociales

(FLACSO-ECUADOR), amllumiquingafl@flacso.edu.ec

\section{Introducción}

Uno de los consensos de la política comparada se centra en la idea de que las elecciones y sus órganos reguladores son el corazón de la democracia representativa (Dahl, 1971; Schattschneider, 1942/1964). A través de estas instituciones los ciudadanos expresan sus preferencias para decidir quién o quiénes serán los titulares de los poderes Legislativo y Ejecutivo. En particular, respecto a las elecciones, tres son las funciones esenciales que cumplen: producir representación, producir gobierno y producir legitimidad (Anduiza y Bosch, 2012, p. 64; Vallés y Bosch, 1997, p. 16). Por su parte, la principal función de los órganos electorales es llevar a cabo procesos limpios, transparentes, justos y eficientes. Como bien lo ha precisado la teoría política en las últimas décadas, las elecciones (y sus órganos) son una condición necesaria, pero no suficiente, para definir un sistema político 


\section{Nuevas
PÁgicas globales}

como democracia, hacerlo conllevaría una comprensión minimalista de ésta, en la cual el sujeto es el votante y no el ciudadano (Brenes, 2009, p. 1; Freidenberg, 2013, p. 18; O’Donnell, 2007, p.14).

Sin ánimo de entrar en la riqueza del debate doctrinario, lo cierto es que en las democracias contemporáneas es central para el juego político el papel de las elecciones -libres, justas, competitivas, igualitarias, universales e imparciales - llevadas a cabo por instituciones igual de transparentes. No en vano, Gianfranco Pasquino (2014) insiste en recordar el carácter técnico que conlleva un proceso electoral y lo concibe como "una característica sustancial e ineludible sin la cual no se puede hablar de democracia ... Si no se vota, si los representantes y gobernantes no son designados mediante procesos electorales, no tenemos democracia de ningún tipo" (p. 30). Igualmente, Romero (2016) recalca que las elecciones han procurado "enraizar la democracia y construir ciudadanía, ser simultáneamente el espacio donde se expresan de forma ordenada las divergencias sociopolíticas y el punto de encuentro de los ciudadanos" (p. 93).

Por ello, el objetivo principal de este trabajo es responder a la siguiente pregunta de investigación: ¿̇la confianza política hacia las elecciones y órganos electorales en el último año de gobierno de Evo Morales se explica por la percepción de la situación económica o por el desempeño presidencial? Si bien en América Latina se ha producido una ola de investigaciones en torno a la confianza política, muy pocos trabajos han abordado el caso boliviano en los últimos años. En general destacan, entre otros, los trabajos de Alcántara (2012), Bargsted y Torcal (2015a; 2015b), Paramio (2015), Mair (2015), Palazuelos (2012) y Zovatto (2018). La mayoría de estos y otros trabajos brindan un 
análisis regional del tema, por eso es pertinente llevar a cabo estudios de caso, especialmente en países que han vivido recientes sobresaltos políticos.

En este sentido, el caso boliviano llama la atención, ya que con la llegada de Evo Morales al poder se dio una reestructuración institucional radical, se fomentaron políticas expansivas del gasto y un mayor intervencionismo estatal. Asimismo, con el "primer presidente indígena" se alteraron las relaciones de poder, en términos fácticos, pero también en el imaginario y en lo simbólico. Cabe recordar que Morales, al igual que otros presidentes de la Marea Rosa, gozó de una gran aprobación ciudadana, ostentó amplios poderes institucionales recogidos en la Constitución y contó con amplias mayorías de su partido en el Legislativo. Esto permitió que el presidente gobernara sin problemas durante muchos años, siempre y cuando las rentas obtenidas por las materias primas hubiesen sido significativas (Campello, 2015; Levitsky y Roberts, 2011; Pogrebinschi, 2013).

A partir del 2014, con la caída de los precios del petróleo los gobiernos progresistas de la Marea Rosa vieron tambalear sus proyectos políticos. En Bolivia, la crisis económica sacó a la luz ciertos problemas estructurales que se creían erradicados con la llegada de Morales. Por ello, en 2016, el pueblo no perdonó sus desatinos políticos ni económicos y el "No" ganó en un referéndum en el que se preguntaba a la ciudadanía si permitía la repostulación de Morales a las próximas elecciones. Desafiando la decisión popular e ignorando su espíritu plebiscitario, Morales acudió al órgano judicial (bajo su poder) para lograr ser candidato presidencial. El fin de esta trama política mostró que el pueblo, bajo ninguna condición, soporta o soportará comportamientos autoritarios de sus gobernantes. Como 


\section{5}

consecuencia, Morales, tras casi 14 años en el poder, tuvo que exiliarse, en medio de protestas y abandono popular (Basabe, 2017; Levitsky y Roberts, 2011; Stefanoni, 2020). Este estudio está estructurado de la siguiente manera. Primero, se realiza una revisión de la literatura sobre la confianza institucional, en la que se abordan, esencialmente, trabajos para América Latina. Segundo, se evalúa la confianza política a nivel regional en seis instituciones (procesos electorales, órganos electorales, poder Ejecutivo, poder Legislativo, poder Judicial y partidos políticos). A la par, se profundiza en dos de ellas a nivel de países. Tercero, se responde a la pregunta de investigación mediante la estimación de un modelo logit ordenado. Por último, se presentan los hallazgos de la investigación y se plantean conclusiones. Para realizar este análisis se utilizan los datos de la encuesta para Bolivia de la oleada 2018/2019, del Proyecto de Opinión Pública de América Latina (LAPOP) de la Universidad de Vanderbilt.

\section{Revisión de la literatura especializada}

La confianza política representa el grado de vinculación entre los ciudadanos con alguno o varios de los objetos del sistema político democrático (Hardin, 2002). Aunque la confianza institucional es una dimensión subjetiva de la política, es un elemento central para las democracias, pues cuando los ciudadanos confían en sus instituciones se producen beneficios para ellos y para las instituciones confiadas (Citrin y Muste, 1999). Zygmunt Bauman y Carlo Bordoni (2016) detallan a la perfección por qué la confianza debe estar en el centro del debate académico:

[Debido a que] la crisis de la democracia, es el colapso de la confianza. La creencia de que los líderes no solo son corruptos o estúpidos, sino 
que son incapaces. La política tiene las manos cortadas. La gente ya no cree en el sistema democrático porque no cumple sus promesas. La crisis contemporánea es una crisis de las instituciones democráticas. (p. 35)

La literatura especializada atribuye a diversos factores explicativos esta tendencia a confiar o no confiar. Por un lado, aquellos de una tradición más culturalista plantean que la confianza política es el resultado de un proceso de socialización que tiende a perdurar en el tiempo y está muy unida a los niveles de modernización económica, social y cultural. Aquí se encuentran los factores sociodemográficos (como la edad, niveles de educación, sexo) y valorativos asociados a la cultura que ostentan los miembros de una sociedad (Almond y Verba, 1965; Booth y Seligson, 2009; Mishler y Rose, 2007; Nohlen, 1995; Pharr y Putnam, 2000). Por otro lado, está la escuela racionalcultural, cuya tesis plantea que la falta de confianza política en las democracias representativas se debe a que no se cumplen las expectativas que los ciudadanos tenían respecto al funcionamiento de las instituciones y sus resultados políticos y económicos (Meer y Dekker, 2011; Norris, 1999; 2011).

Las evaluaciones que influyen en el deterioro de la confianza individual pueden estar fundamentadas en dos tipos de razonamientos. El primero está más relacionado con el diseño y el funcionamiento institucionales $y$ sus resultados políticos. Los estudios sobre el diseño institucional destacan el papel del sistema electoral, el grado de desarrollo de los derechos civiles y libertades y la fragmentación del sistema de partidos (Criado y Herreros, 2007; Ross y Escobar-Lemmon, 2011). En relación con el argumento de atribución de responsabilidades y sus 


\section{sat}

resultados, algunos de los principales factores abordados en la literatura son el grado de corrupción y el desempeño gubernamental (Torcal y Montero, 2006).

El segundo grupo de explicaciones son más instrumentales y unen directamente la confianza política a los resultados económicos del sistema. Según Bargsted y Torcal (2015a), este supuesto económico esconde dos aspectos relevantes. Primero, la mayoría de la evidencia empírica con respecto a esta relación se sustenta en la evaluación sociotrópica de la situación económica por parte del entrevistado y no deja de estar exenta de un filtro partidista. Segundo, estas valoraciones serían en parte reflejo del juego político y partidista. Por ende, podrían reflejar una cierta politización de la confianza política. Asimismo, es preciso mencionar los estudios de naturaleza psicológico-social que pretenden explicar la confianza institucional a partir de variables como la confianza interpersonal, el interés en la política y la satisfacción con la vida; se encuentra también un grupo de explicaciones de orden sociocultural relacionadas con la capacidad de los individuos de participar voluntariamente en la comunidad a fin de construir una cultura cooperativa (Bargsted, Castilllo y Somma, 2017; Corbacho, Philipp y Ruiz, 2015; Newton y Norris, 2000).

\section{Confianza institucional en América Latina}

Los datos de la ronda 2018/2019 del Proyecto de Opinión Pública de América Latina (LAPOP) permiten comparar los niveles de confianza entre varias instituciones políticas en los países de la región. Esta ronda de LAPOP contó con más de 31.050 entrevistas, provenientes de 20 países de América y el Caribe, a los cuales se les realizó la siguiente pregunta: "¿Hasta qué punto tiene usted confianza en 
las elecciones, partidos políticas (...)?”. Las respuestas se basaron en una escala de 1 a 7 , donde ' 1 ' indica "nada" y '7' indica "mucho". Para este estudio se han usado solamente los datos de 17 países de América Latina (Argentina, Bolivia, Brasil, Chile, Colombia, Costa Rica, República Dominicana, Ecuador, El Salvador, Guatemala, Honduras, México, Nicaragua, Panamá, Paraguay, Perú y Uruguay). No se incluyeron Venezuela y Haití, pues LAPOP decidió no realizar encuestas en estos países debido a la inestabilidad política.

En la Tabla 1 los números hablan por sí solos. La media de confianza en que se mueven las elecciones, los órganos electorales, los partidos políticos, el poder Legislativo, el poder Judicial y el poder Ejecutivo no supera los 4 puntos en la escala de confianza presentada por LAPOP. Mientras que los procesos electorales ostentan el promedio más alentador, en el polo opuesto los partidos políticos destacan por sus valores alarmantes. En conjunto, estos datos revelan que las democracias latinoamericanas generan instituciones en las cuales la gente no confía. Cabe considerar que la desconfianza que se observa reside en que la percepción de los ciudadanos hoy es que no tienen voz, no tienen acceso a oportunidades, sus ingresos son precarios y bajos, sus gobernantes son egoístas y que la política es complicada.

Tabla1. Confianza política en América Latina (2018/2019)

\begin{tabular}{|l|c|c|c|}
\hline \multicolumn{1}{|c|}{ Institución política } & Media* & Mínimo & Máximo \\
\hline Procesos electorales & $3,8(26.142)$ & 1 & 7 \\
\hline Órganos electorales & $3,7(6.182)$ & 1 & 7 \\
\hline Poder Ejecutivo & $3,5(26.209)$ & 1 & 7 \\
\hline Poder Legislativo & $3,4(25.782)$ & 1 & 7 \\
\hline
\end{tabular}




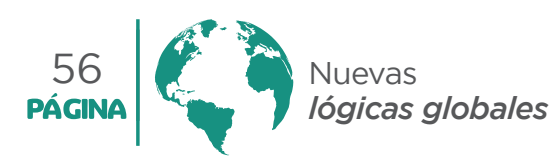

\begin{tabular}{|l|c|c|c|}
\hline Institución política & Media* & Mínimo & Máximo \\
\hline Poder Judicial & $3,4(6.338)$ & 1 & 7 \\
\hline Partidos políticos & $2,7(26.099)$ & 1 & 7 \\
\hline
\end{tabular}

* Nota: Los valores de las celdas muestran los promedios del nivel de confianza en una escala de 1 (nada) a 7 (mucha); número de observaciones entre paréntesis.

Fuente: Elaboración propia, con datos de LAPOP (2019).

Los datos del Barómetro de las Américas también revelan que el promedio de confianza en las elecciones en los países latinoamericanos es 3,8. Se trata de un nivel de confianza neutral (equivalente a 5,4 en una escala de 0 a 10), ya que el promedio apenas sobrepasa por 0,3 la media de la escala. Si bien el último informe de LAPOP (2019) revela que el promedio regional de confianza apenas ha variado desde el Barómetro de 2008 (3,9 en 2008, 4,1 en 2012, 3,8 en 2016 y 3,7 en 2018/2019), estos datos dejan mucho que desear, pues uno de los rasgos característicos de la región es su efervescencia electoral. Los resultados cerrados en algunas elecciones, además de varias situaciones de ventajismo electoral caracterizadas por falta de condiciones de equidad e imparcialidad, la independencia cuestionada de los organismos electorales, el uso y abuso de los recursos del Estado a favor del oficialismo y el financiamiento político irregular, son algunos de los factores que han erosionado la credibilidad de esta institución y, en consecuencia, han sido promotores de varias crisis electorales en la región ( $p$. ej.: Bolivia y República Dominicana) (Zovatto, 2018, p. 14).

Al analizar en el ámbito particular de los países la confianza en dos instituciones esenciales de las democracias latinoamericanas - procesos electorales y partidos políticos-, encontramos hallazgos interesantes 
(Figura 1). Para los procesos electorales, se observaron los siguientes resultados: Honduras y República Dominicana son los países con niveles más bajos de confianza; en ambos casos, el nivel de confianza está por debajo de 3,8 (la media regional). Uruguay se sitúa justo en el polo opuesto: presenta un nivel de confianza en las elecciones $(5,1)$ muy por encima de la media regional. Los catorce países restantes se ubican entre estas dos posiciones extremas, aunque con diferencias destacadas entre ellos. Mientras que Colombia, Brasil, Panamá, Guatemala, Bolivia, Paraguay, Perú y El Salvador se hallan por debajo de la media latinoamericana, los demás países se sitúan en la media o por encima, especialmente, Chile, Costa Rica y Uruguay.

Estos datos llaman la atención, pues los procesos electorales se han convertido en "eventos rutinarios" que van adquiriendo "vida propia" (Schedler, 2002). El periodo comprendido entre 2017 y 2019 ha sido descrito como "la época del maratón electoral”, pues 15 de los 18 países celebraron elecciones durante este lapso. En el año 2017, se celebraron elecciones en Chile, Ecuador y Honduras, mientras en 2018 las hubo en Brasil, Colombia, Costa Rica, México, Paraguay y Venezuela. En 2019, se realizaron tres elecciones presidenciales en América Central (El Salvador, Guatemala y Panamá) y tres elecciones presidenciales en América del Sur (Argentina, Bolivia y Uruguay) (Anderson et al., 2005; IDEA Internacional, 2019, p. 46). 

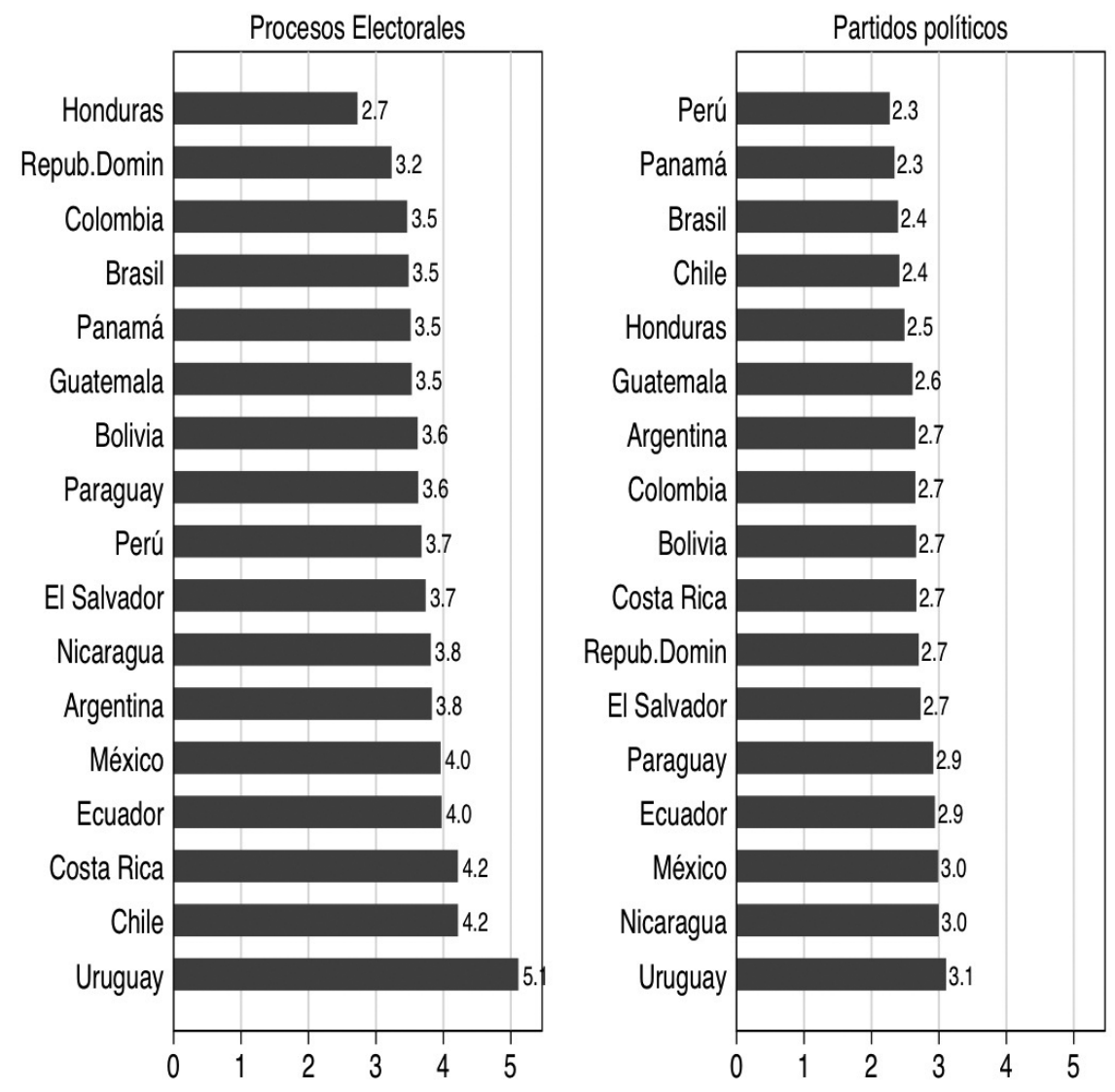

Figura 1. Confianza política en 17 países de América Latina (2018/2019)

Fuente: Elaboración propia, con datos de LAPOP (2019). Promedio del nivel de confianza en una escala de 1 (nada) a 7 (mucha).

Si bien Bolivia no es el país con los peores resultados, sus datos dan cuenta de la desafección institucional en la que transitaba Evo Morales durante su último año de gobierno y no cabe duda de que fue uno de sus principales retos políticos. Con este escenario se realizaron las elecciones presidenciales de octubre de 2019, durante las cuales salieron a la luz ciertos problemas técnicos. Como 
consecuencia, estas elecciones fueron percibidas como fraudulentas y corruptas. A la par, el órgano electoral perdió legitimidad, al ser considerado como una maquinaria corrompida por el Ejecutivo y vendida a su favor, todo lo cual generó un gran estallido social que culminó con la destitución de Morales y su ostracismo político. Esto demuestra que un voto público por sí solo no resuelve los profundos problemas sociales y políticos, y menos aún si las instituciones que los regulan están deslegitimizadas y erosionadas (Barrientos, 2020; Castorena et al., 2020; Stefanoni, 2020).

Por otra parte, los datos sobre la confianza en los partidos políticos son aun más desalentadores. La media latinoamericana se sitúa en 2,7 en la escala de confianza. Perú, Panamá, Brasil, Chile, Honduras y Guatemala están por debajo de la media regional. Sin embargo, el resto de países no sobrepasan los tres puntos de confianza. Destacan México, Nicaragua y Uruguay con los valores más altos. Esta es una situación preocupante, ya que los partidos siguen siendo los actores centrales de los sistemas políticos democráticos, pues cumplen con funciones críticas como la de agregar y canalizar los intereses y demandas ciudadanas, fomentar la socialización política, la movilización de la opinión pública y la selección de élites. La razón de ser de los partidos políticos es garantizar con su presencia y su actuación el pluralismo político y la competencia electoral. Sin ellos, resulta imposible el juego democrático (Alcántara, 2009; Mainwaring 2006; Mair, 2015; Sánchez, 2008; Schattschneider, 1942/1964).

En concreto, si bien la rutinización de lo electoral y la competencia partidista son características relevantes de la vida política de la región y reafirman la convicción de que "los partidos importan" y de que "el voto es la 


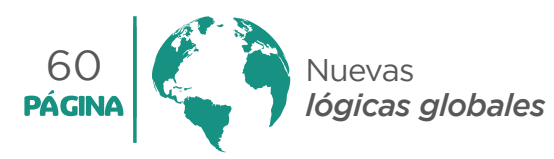

única vía legítima para acceder al poder", los datos presentados revelan que los ciudadanos latinoamericanos deben convivir con instituciones en las que no confían. Como consecuencia, esto desvirtúa la naturaleza misma de la representación y participación ciudadanas, además, profundiza los sentimientos de alienación y polarización social. Uno de los casos que llama la atención es Bolivia, no por sus datos alarmantes sino por las catastróficas consecuencias sociales y políticas que vivió el país andino en el año 2019 (Schattschneider, 1942/1964; Mair 2015).

\section{Bolivia en la encrucijada}

La denominada "democracia pactada" boliviana fue un periodo de estabilidad política, económica y social que abarca desde 1985 hasta el año 2002, casi dos décadas de estabilidad democrática en un país donde el constante asalto al estado de derecho y los largos periodos de dictaduras militares eran eventos casi normalizados. Pese a ello, el panorama político empezó a cambiar a inicios del siglo XXI, primero, con la súbita emergencia del Movimiento al Socialismo (MAS) como segunda fuerza política detrás del Movimiento Nacionalista Revolucionario (MNR) y, segundo, con el colapso del sistema de partidos y la crisis de representación en el año 2006. Desde entonces, gracias a la victoria electoral del MAS y la omnipresencia de su líder Evo Morales, quien trajo consigo la promesa del cambio y la inclusión étnica en la estructura estatal, el horizonte político y social de Bolivia cambió radicalmente (Barrientos, 2020; Tanaka, 2015, p. 172).

En particular, Evo Morales se convirtió en el eje cardinal de la arena política, logró concentrar una vasta base electoral y gozar de altos índices de popularidad. Como consecuencia, en Bolivia se dio una perniciosa personalización de la política en torno al ejecutivo. En este 
escenario, otras instituciones también se vieron envueltas por la omnipresencia de Morales, esencialmente el poder legislativo, donde el presidente contaba con una mayoría partidaria; y el poder judicial, pues los jueces eran afines al Gobierno. Esta politización quebrantó uno de los cánones esenciales de las poliarquías latinoamericanas: la separación de poderes. Además, dejó constancia de que el Presidente no era un mero actor político, sino que era el jugador de veto más importante del país.

Un claro ejemplo de la politización institucional y vulneración del principio de separación de poderes fue la candidatización de Morales para las elecciones de 2019. Morales logró presentarse a las elecciones porque, primero, ignoró el referéndum constitucional del 21 de febrero de 2016 en el que el "No" ganó con un 51,3 \%, un resultado que lo incapacitaba para una reelección. Sin embargo, un año después, el Tribunal Supremo Constitucional autorizaba su habilitación, basado en la consideración que la reelección presidencial era un derecho humano y, por lo tanto, el mandatario podía presentarse a las siguientes elecciones sin que ello conllevara una sanción política o jurídica (Barrientos, 2020; Flores, 2019).

Así se arribó a las elecciones presidenciales del 20 de octubre de 2019, donde el futuro político del "primer presidente indígena" y la estabilidad del país estaban en juego. La noche del 20 de octubre concluyó con el ballotage como un resultado probable: la Trasmisión de Resultados Electorales Preliminares (TREP) fue cortada cuando el conteo alcanzaba solamente el $83 \%$ de las actas y la diferencia era de siete puntos. Al día siguiente, cuando se completó el TREP, ya se anunciaba por todo el país un ajustado triunfo en primera vuelta para Morales. Estos datos fueron confirmados días después por el 
conteo oficial, que concluyó que Morales había obtenido 47,08 \% y Carlos Mesa, 36,52 \%, es decir, 10,54 puntos porcentuales de diferencia entre ambos contendientes (Stefanoni, 2019).

Ante este escenario dudoso, los resultados fueron vistos como fraudulentos. Como consecuencia, durante 21 días una gran movilización ciudadana inundó el país (la autodenominada "Revolución de las Pititas") demandando el respeto del voto de las elecciones generales del 20 de octubre de 2019. A la par, otros eventos profundizaron el ambiente de crisis: el motín de la policía, el informe preliminar de la Organización de los Estados Americanos donde se anunciaba irregularidades en el proceso electoral, y la recomendación al mandatario por parte de organizaciones obreras y sindicales y de las Fuerzas Armadas de que renunciase al cargo. Temiendo por su vida, Morales decidió abandonar el Palacio Quemado después de un mandato de casi 14 años y lo hizo de la peor forma posible, presionado por una movilización en las calles nunca antes vista y por motines policiales en todos los departamentos del país (Barrientos, 2020; Flores, 2019).

La renuncia y salida al exilio de Evo Morales, no solo acabó de manera repentina con el llamado "proceso de cambio", también significó el descrédito de las elecciones y del Tribunal Electoral boliviano, tras la anulación de los comicios de octubre en medio de denuncias de fraude (Stefanoni, 2020). Si bien los datos de LAPOP (2019) ya revelaban que la falta de confianza política era uno de los retos políticos del mandatario, esto no mermó las ansias de poder y perpetuación de Morales. La encuesta del Barómetro de las Américas para Bolivia se llevó a cabo entre mayo y junio de 2019 y, por ende, da cuenta del sentimiento de confianza antes de la crisis y nos permite 
indagar en los factores determinantes de la confianza hacia las elecciones y el Tribunal Electoral a pesar de la crisis política que se avecinaba.

\section{Hipótesis y variables independientes}

A partir de la revisión de la literatura especializada y el estudio del contexto boliviano, se formulan dos hipótesis principales, las cuales están relacionadas con las explicaciones de carácter racional-cultural y tienen que ver con la evaluación de la economía y la aprobación del desempeño presidencial. El argumento central de estas variables es que la falta de confianza de los ciudadanos puede ser causada por los largos periodos de expectativas frustradas, que son producto de la percepción individual de un funcionamiento gubernamental fallido y de un mal desempeño económico (Anderson, 2009; Bargsted et al., 2017; Hagopian y Mainwaring, 2005; Ross y EscobarLemmon, 2011).

Por ende, (H1) a medida que la evaluación del estado de la economía personal y del país empeora, la gente confía menos en los procesos electorales y órganos electorales. Asimismo, (H2) una evaluación desfavorable al trabajo del presidente tenderá a reducir la confianza política en estas instituciones. Los datos utilizados para esta investigación provienen de la oleada de encuestas 2018/2019 realizadas a los ciudadanos bolivianos, llevadas a cabo por el Proyecto de Opinión Pública de América Latina (LAPOP, 2019) de la Universidad de Vanderbilt, iniciado hace más de dos décadas por Mitchell A. Seligson y dirigido por Elizabeth J. Zechmeister. La variable dependiente de nuestra investigación es la confianza política en las elecciones y los procesos electorales. Esta variable se midió a través de la siguiente pregunta de LAPOP 2018/2019: 
En esta tarjeta hay una escalera con gradas numeradas del uno al siete, en la cual 1 es la grada más baja y significa NADA y el 7 es la grada más alta y significa MUCHO. B13. ¿Hasta qué punto tiene confianza usted en los procesos electorales? B21. ¿Hasta qué punto tiene confianza usted en el órgano electoral?

En esta investigación se propone un modelo logit ordenado que se ajusta mejor cuando las variables dependientes son de naturaleza categórica ordenada, como en este caso, en el que la variable confianza instituciona/se mide en una escala de1 (Nada) a 7 (Mucho). Para corroborar la primera hipótesis, la percepción de la economía personal y la evaluación de la economía nacional sirven de variables explicativas. Ambas toman valores de 1 (mejor), 2 (Igual) y 3 (Peor). Si se apoya la hipótesis, estas variables deberían tener un impacto negativo en la probabilidad de confiar en todas estas instituciones. En la segunda hipótesis, nuestra variable explicativa es la aprobación del trabajo del presidente y toma valores de 1 (Muy bueno) a 5 (Muy malo). Si la hipótesis es correcta, esta variable debería ostentar un impacto negativo en la probabilidad de confiar.

También, se consideran otros factores sociodemográficos. Primero, debido a las desigualdades de género latentes en América Latina y, especialmente, en Bolivia, es posible que existan diferencias de género en la confianza institucional. Diversos estudios sobre confianza política en países de Europa del Este corroboran que el género es un factor importante, tanto para la confianza en las instituciones como para la satisfacción con el funcionamiento de la democracia (Kucel, 2004). Para género se creó una variable ficticia llamada Mujer, donde 1 indica mujeres y 
0 indica hombres. Se espera un signo negativo, ya que se considera que las mujeres tienden a no confiar en estas instituciones. Otra posible explicación es la edad y esta opera como variable continua. Se espera que entre más edad tenga el encuestado es más probable que confíe en estas instituciones (Abrajano y Álvarez, 2010).

Asimismo, se considera como factor determinante el nivel educativo, pues la literatura plantea que los individuos con mayores recursos (humanos y económicos) son más proclives a tener actitudes favorables hacia el sistema democrático (Anduiza y Bosch, 2009). La variable educación se categorizó en Ninguno, Primaria, Secundaria (categoría de referencia) y Universidad. Se espera un signo positivo entre la categoría superior y negativo en las inferiores. Por último, se han considerado las variables de eficacia externa y aprobación a la re-postulación. En particular, la eficacia externa es un factor esencial, pues se basa en la expectativa de que las autoridades toman en cuenta a los ciudadanos y serán capaces de responder eficientemente a sus demandas (Montero et al., 1998). Esta variable es medida en una escala de 1 (Muy en desacuerdo) a 7 (Muy de acuerdo), se espera un signo positivo. Por su parte, la variable aprobación a la repostulación es dicotómica, donde 1 es Aprobación y 2 No aprobación, se espera que quienes la aprueban confían más en las instituciones. 


\section{Resultados}

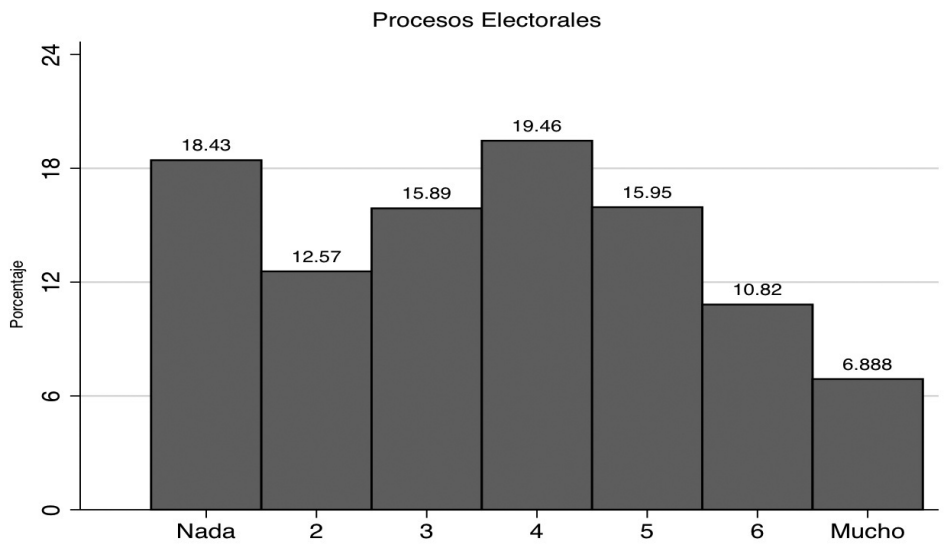

Figura 2. Confianza política en los procesos electorales, variable dependiente

Fuente: Elaboración propia, con datos de LAPOP (2019).

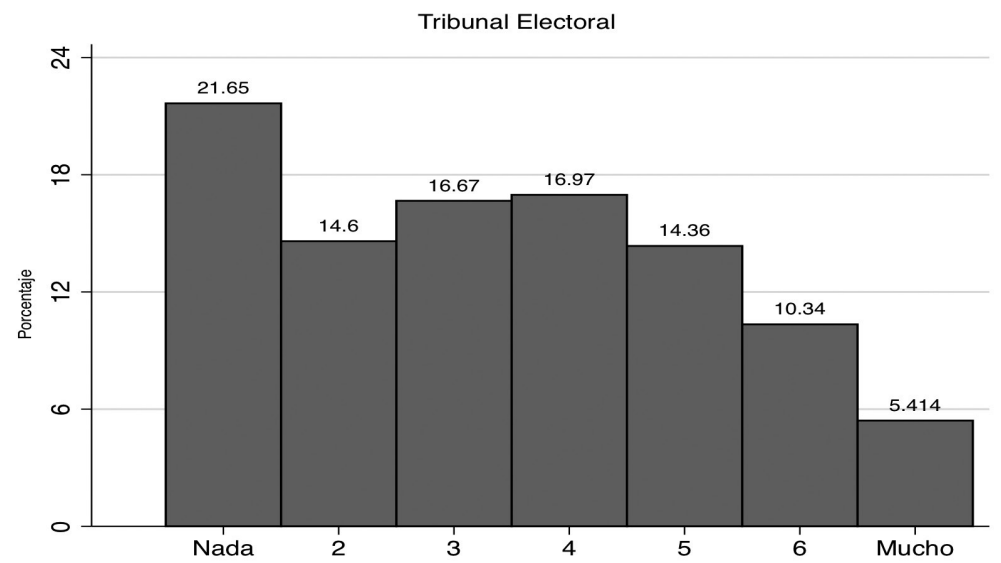

Figura 3. Confianza política en el Tribunal Electoral, variable dependiente

Fuente: Elaboración propia, con datos de LAPOP (2019) 
Las Figuras 2 y 3 presentan datos interesantes. En la oleada $2018 / 2019$, se observa que el $46,86 \%$ de los entrevistados bolivianos se ubican en las tres categorías más bajas de confianza hacia las elecciones, mientras que el 52,92 \% de los entrevistados se encuentran en las mismas categorías para el órgano electoral. Sin embargo, se destacan ciertos aspectos en ambas figuras. Primero, aunque la mayor cantidad de entrevistados se ubican en la categoría 4 de la escala de confianza en las elecciones, la categoría 1 también ostenta un porcentaje considerable (18,43\%), asimismo, se observa una distribución asimétrica positiva y platicúrtica (aplanada). En cuanto a la confianza en el Tribunal Electoral, la Figura 3 revela que la mayoría de encuestados se ubican en la categoría 1 (21,65 \%) seguido de la categoría 5 con 16,97 \%. También, se advierte una distribución asimétrica positiva y platicúrtica.

Por otra parte, las Tablas 2 y 3 presentan ciertos hallazgos iniciales que prueban nuestras afirmaciones. Algo que llama la atención es que, en tanto peor es la percepción de la economía personal, menor es la confianza en las elecciones y el Tribunal Electoral. Esta tendencia también se observa en cuanto a la percepción de la económica nacional. Los datos que más llaman la atención tienen que ver con el desempeño gubernamental. En este sentido, para ambas instituciones se observa que a una "Muy mala" percepción del desempeño gubernamental, los encuestados muestran menor confianza institucional. Estos hallazgos se sustentan con los resultados del estadístico $\mathrm{X}^{2}$ (Chi) correspondiente. Este es estadísticamente significativo en todos los análisis bivariables a un $\mathrm{p}<0.05$. Por ende, se rechaza la hipótesis nula de que no hay asociación entre estas variables. 
La medida de asociación de Spearman vuelve a confirmar la existencia de asociación. Por un lado, las variables independientes de percepción de la economía personal y nacional ostentan una asociación negativa débil con ambas variables dependientes. Por otro lado, la variable independiente desempeño gubernamental muestra una asociación negativa fuerte tanto con las elecciones (-0.4645) como con el Tribunal Electoral (-0.4227). Los resultados de estas asociaciones binarias dan evidencia inicial hacia las hipótesis planteadas. Para conferir mayor validez estadística a estos hallazgos preliminares, se estima un modelo logit ordenado, debido a la naturaleza categórica de nuestras variables dependientes. 


\begin{tabular}{|c|c|c|c|c|c|c|c|c|c|c|c|}
\hline$\frac{n}{0}$ & \multirow{10}{*}{ 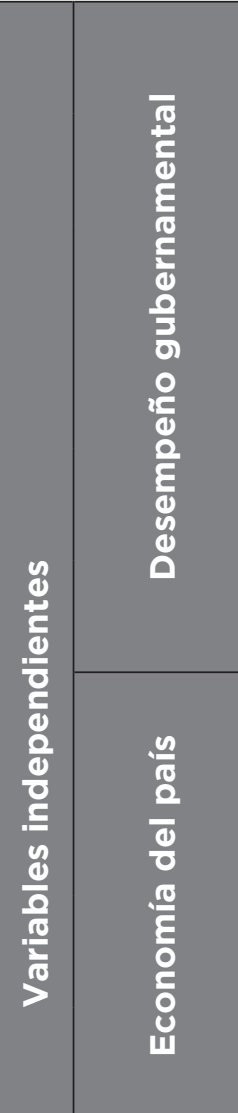 } & Total & $\left|\begin{array}{c}\infty \\
N \\
\infty \\
\infty \\
\sim\end{array}\right|$ & $\begin{array}{l}i n \\
\mathfrak{N}\end{array}$ & $\begin{array}{l}\hat{\sigma} \\
\text { ம̊ }\end{array}$ & 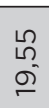 & $\begin{array}{l}\hat{\Omega} \\
\text { nీ }\end{array}$ & $\begin{array}{l}0 \\
\infty \\
0 \\
0\end{array}$ & $\begin{array}{l}6 \\
\infty \\
0 \\
6\end{array} \mid$ & 100,00 & \multirow{6}{*}{ 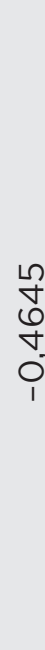 } \\
\hline$\frac{y}{0}$ & & Muy Malo & $\begin{array}{l}\bar{\sigma} \\
\bar{\kappa}\end{array}$ & 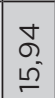 & $\stackrel{\stackrel{L}{q}}{-}$ & $\begin{array}{l}0 \\
\infty \\
\omega^{-1}\end{array}$ & $\begin{array}{l}\circ \\
\text { o } \\
\text { v }\end{array}$ & $\begin{array}{l}0 \\
\text { ๙ } \\
\text { i }\end{array}$ & $\begin{array}{l}0 \\
0 \\
0\end{array}$ & 100,00 & \\
\hline U & & Malo & $\begin{array}{l}\hat{m} \\
\tilde{q} \\
\text { q }\end{array}$ & $\begin{array}{l}\sim \\
\infty \\
⺊ \\
\sim\end{array}$ & $\begin{array}{l}0 \\
\dot{\sigma} \\
6 \\
6\end{array}$ & $\begin{array}{l}\stackrel{g}{+} \\
\text { の̆ }\end{array}$ & $\frac{6}{m}$ & $\begin{array}{l}\circ \\
\infty \\
N^{-1}\end{array}$ & ᄋㅛ & 100,00 & \\
\hline o & & $\begin{array}{c}\text { Ni Bueno/ } \\
\text { Ni Malo }\end{array}$ & $\begin{array}{l}\stackrel{N}{ \pm} \\
\stackrel{E}{*}\end{array}$ & $\begin{array}{l}\infty \\
\stackrel{n}{\sim} \\
\sim\end{array}$ & 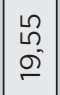 & $\hat{\widehat{\omega}}$ & 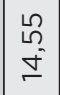 & $\begin{array}{l}\hat{\varphi} \\
\ddot{6}\end{array}$ & 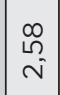 & 100,00 & \\
\hline O & & Bueno & $\mid \begin{array}{l}\stackrel{2}{R} \\
\infty\end{array}$ & \begin{tabular}{|l|}
$M$ \\
\multirow{+}{M}{} \\
$\infty$
\end{tabular} & $\begin{array}{l}\infty \\
\infty \\
\omega \\
\omega\end{array}$ & $\begin{array}{l}\stackrel{0}{\llcorner} \\
\stackrel{\sim}{N}\end{array}$ & N & 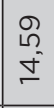 & $\begin{array}{l}\text { O } \\
\stackrel{1}{ } \\
\infty\end{array}$ & 100,00 & \\
\hline 气 & & $\begin{array}{l}\text { Muy } \\
\text { bueno }\end{array}$ & $\begin{array}{l}O \\
\stackrel{1}{1} \\
M^{-}\end{array}$ & $\stackrel{\text { O }}{i}$ & $\begin{array}{l}\stackrel{\mathscr{N}}{\mathrm{U}} \\
0\end{array}$ & $\begin{array}{l}\infty \\
\infty \\
\infty \\
\infty\end{array}$ & $\mid \begin{array}{l}\infty \\
0 \\
0 \\
0\end{array}$ & $\begin{array}{l}\hat{\infty} \\
\stackrel{\infty}{N}\end{array}$ & ล̊ & 100,00 & \\
\hline$\pi$ & & Total & $\mid \begin{array}{c}\hat{f} \\
\infty \\
\infty^{-}\end{array}$ & $\mid \begin{array}{l}0 \\
0 \\
1 \\
0\end{array}$ & $\begin{array}{l}M \\
\infty \\
\omega \\
\omega\end{array}$ & $\begin{array}{l}M \\
M \\
\text { D }\end{array}$ & $\begin{array}{l}\overline{0} \\
0 \\
0\end{array}$ & 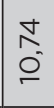 & $\begin{array}{l}M \\
0 \\
6\end{array}$ & 100,00 & \multirow{4}{*}{$\stackrel{n}{n}$} \\
\hline is & & Peor & 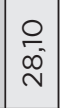 & 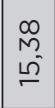 & $\begin{array}{l}\widehat{E} \\
\omega^{*}\end{array}$ & $\frac{1}{6}$ & $\begin{array}{l}M \\
\infty \\
O \\
O\end{array}$ & $\frac{6}{\infty}$ & $\frac{\infty}{\omega^{n}}$ & 100,00 & \\
\hline 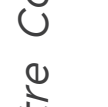 & & Igual & $\frac{6}{\omega}$ & \begin{tabular}{|l|}
$\underline{Q}$ \\
$M^{2}$ \\
$\underline{m}^{2}$
\end{tabular} & $\begin{array}{l}\hat{O} \\
\stackrel{0}{\sigma}\end{array}$ & $\begin{array}{l}\stackrel{\infty}{\stackrel{n}{N}} \\
\stackrel{n}{n}\end{array}$ & 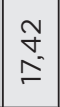 & $\begin{array}{l}\infty \\
\infty \\
\infty \\
\infty\end{array}$ & 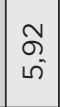 & 100,00 & \\
\hline (1) घ & & Mejor & $\begin{array}{l}L \\
M \\
\infty \\
\infty\end{array}$ & $\frac{\varphi}{\pi}$ & $\begin{array}{l}0 \\
0 \\
M^{-}\end{array}$ & $\begin{array}{l}0 \\
\stackrel{2}{0}\end{array}$ & $\begin{array}{c}\mathscr{\sigma} \\
\stackrel{\sim}{\sim}\end{array}$ & $\frac{\infty}{\check{\Sigma}}$ & $\begin{array}{l}\infty \\
0 \\
0 \\
0\end{array}$ & 100,00 & \\
\hline 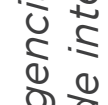 & \multirow{4}{*}{ 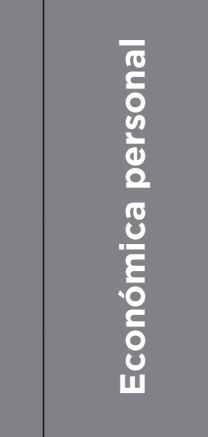 } & Total & $\begin{array}{l}\underset{y}{y} \\
\infty \\
\stackrel{0}{0}\end{array}$ & $\mid \begin{array}{c}\infty \\
\stackrel{n}{n} \\
\stackrel{\sim}{\simeq}\end{array}$ & $\begin{array}{l}0 \\
\infty \\
\omega^{-} \\
\end{array}$ & $\begin{array}{l}\text { 을 } \\
\stackrel{2}{n}\end{array}$ & $\begin{array}{l}\infty \\
\sigma \\
\stackrel{5}{\curvearrowleft}\end{array}$ & $\begin{array}{l}\infty \\
\infty \\
0\end{array}$ & $\begin{array}{l}\hat{\infty} \\
0 \\
6\end{array}$ & 100,00 & \multirow{4}{*}{ 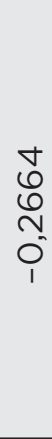 } \\
\hline 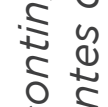 & & Peor & $\stackrel{\cong}{\check{\sim}}$ & 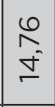 & $\stackrel{\stackrel{5}{N}}{\stackrel{5}{N}}$ & $\begin{array}{l}0 \\
\frac{1}{6}\end{array}$ & $\begin{array}{l}0 \\
1 \\
0 \\
0\end{array}$ & $\begin{array}{l}\hat{0} \\
\infty\end{array}$ & $\begin{array}{l}\overline{6} \\
\tau\end{array}$ & 100,00 & \\
\hline $\begin{array}{l}0 \\
0 \\
0 \\
0\end{array}$ & & Igual & $\begin{array}{l}\stackrel{\omega}{\infty} \\
\infty \\
6 \\
6\end{array}$ & $\begin{array}{l}\mathfrak{N} \\
\mathfrak{N}\end{array}$ & $\begin{array}{l}\stackrel{\mathscr{M}}{M} \\
\stackrel{\omega}{n}\end{array}$ & $\begin{array}{l}\stackrel{\infty}{N} \\
\stackrel{N}{N}\end{array}$ & $\begin{array}{l}\mathscr{N} \\
N \\
N\end{array}$ & $\begin{array}{l}\infty \\
\stackrel{\infty}{\sigma} \\
\sigma^{-}\end{array}$ & $\begin{array}{l}\kappa \\
\omega^{\circ}\end{array}$ & 100,00 & \\
\hline$\frac{0}{0} \frac{0}{0}$ & & Mejor & $\left|\begin{array}{l}\hat{\alpha} \\
\infty\end{array}\right|$ & $\begin{array}{l}\hat{\alpha} \\
\infty\end{array}$ & $\mid$\begin{tabular}{l}
$O$ \\
$\dot{y}$ \\
\multirow{t}{\pm}{}
\end{tabular} & $\begin{array}{l}M \\
\stackrel{M}{-}\end{array}$ & 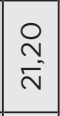 & $\begin{array}{l}M \\
0 \\
0 \\
0\end{array}$ & 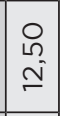 & 100,00 & \\
\hline 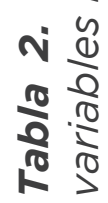 & $\begin{array}{c}\text { Variable } \\
\text { dependiente }\end{array}$ & $\begin{array}{l}\text { Procesos } \\
\text { electorales }\end{array}$ & $\begin{array}{l}0 \\
0 \\
\pi \\
2\end{array}$ & $\sim$ & $m$ & $\nabla$ & 6 & 6 & 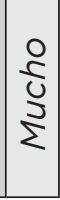 & $\begin{array}{l}\text { Dे } \\
\text { م }\end{array}$ & $\begin{array}{l}\frac{5}{0} \\
\frac{1}{1} \\
0 \\
0 \\
\text { जी }\end{array}$ \\
\hline
\end{tabular}




\begin{tabular}{|c|c|c|c|c|c|c|c|c|c|c|c|}
\hline$\frac{d}{0}$ & \multirow{10}{*}{ 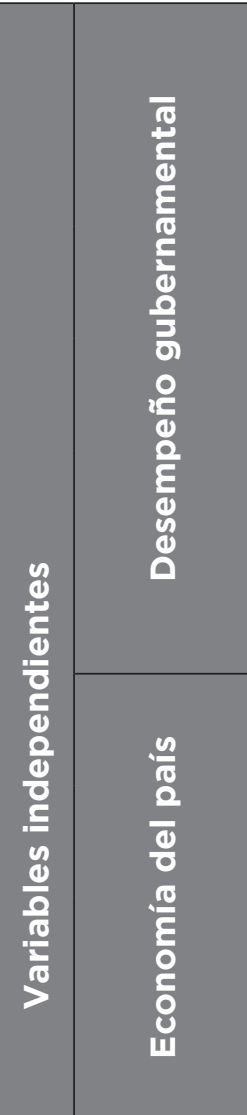 } & Total & $\begin{array}{l}\dot{j} \\
\dot{N}\end{array}$ & $\begin{array}{l}\overline{0} \\
\dot{ \pm}\end{array}$ & $\begin{array}{l}9 \\
6 \\
6\end{array}$ & $\begin{array}{l}M \\
0 \\
6 \\
6\end{array}$ & 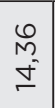 & $\begin{array}{l}M \\
M \\
O \\
O\end{array}$ & $\begin{array}{l}\stackrel{8}{8} \\
\text { in }\end{array}$ & 100,00 & \multirow{6}{*}{\begin{tabular}{l} 
స̃ \\
\multirow{+}{*}{} \\
0 \\
1
\end{tabular}} \\
\hline$\frac{1}{9}$ & & Muy Malo & 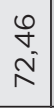 & 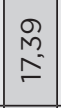 & $\begin{array}{l}\infty \\
\infty \\
\Gamma^{-1}\end{array}$ & 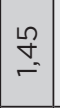 & $\stackrel{\stackrel{n}{+}}{\leftarrow}$ & $\begin{array}{l}0 \\
0 \\
0 \\
0\end{array}$ & $\stackrel{\stackrel{\sim}{+}}{\leftarrow}$ & 100,00 & \\
\hline$\frac{\lambda}{\pi}$ & & Malo & 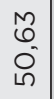 & $\begin{array}{l}\stackrel{\infty}{\infty} \\
m \\
\infty \\
\infty\end{array}$ & $\frac{\sigma}{5}$ & $\begin{array}{l}0 \\
0 \\
6 \\
6\end{array}$ & $\begin{array}{l}6 \\
0 \\
\text { ம் }\end{array}$ & $\begin{array}{l}m \\
\stackrel{2}{n} \\
\sim\end{array}$ & $\stackrel{\overbrace{}}{-}$ & 100,00 & \\
\hline 文 & & $\begin{array}{l}\text { Ni Bueno/ } \\
\text { Ni Malo }\end{array}$ & $\begin{array}{l}\hat{O} \\
\text { Ǹ }\end{array}$ & $\stackrel{\stackrel{n}{ }}{\check{I}}$ & $\stackrel{\simeq}{\mathscr{\sigma}}$ & $\frac{n}{\check{I}}$ & $\begin{array}{l}\stackrel{L}{\circ} \\
\stackrel{M}{\square}\end{array}$ & 呑 & $\begin{array}{l}\infty \\
\infty \\
i \\
i\end{array}$ & 100,00 & \\
\hline$\stackrel{\sigma}{\S}$ & & Bueno & $\begin{array}{l}\stackrel{+}{0} \\
\infty \\
0 \\
\end{array}$ & $\begin{array}{l}\hat{\sigma} \\
\text { ஸे }\end{array}$ & 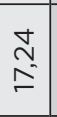 & $\overline{i n}$ & $\stackrel{\stackrel{\sim}{N}}{=}$ & $\begin{array}{l}\hat{\sigma} \\
\text { ป } \\
\end{array}$ & $\underset{N}{N}$ & 100,00 & \\
\hline$\frac{1}{1}$ & & $\begin{array}{l}\text { Muy } \\
\text { bueno }\end{array}$ & \begin{tabular}{l}
$\stackrel{\varphi}{N}$ \\
\multirow{\sigma}{*}{}
\end{tabular} & $\begin{array}{l}\underset{N}{\sim} \\
\sim \\
\sim\end{array}$ & $\begin{array}{l}m \\
\tilde{\sigma} \\
\sigma\end{array}$ & $\begin{array}{l}0 \\
\infty \\
\pm \\
\pm\end{array}$ & $\begin{array}{l}\underset{1}{\infty} \\
\stackrel{+}{\sim}\end{array}$ & $\begin{array}{l}M \\
\stackrel{M}{2} \\
\stackrel{2}{N} \\
\stackrel{n}{N}\end{array}$ & $\begin{array}{l}\bar{M} \\
\varphi^{-}\end{array}$ & 100,00 & \\
\hline ఏ) & & Total & 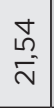 & 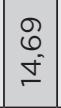 & $\begin{array}{l}0 \\
6 \\
6\end{array}$ & \begin{tabular}{|l|}
$\infty$ \\
0 \\
6 \\
6
\end{tabular} & $\begin{array}{l}\bar{\Sigma} \\
\dot{ \pm} \\
\dot{ \pm}\end{array}$ & $\begin{array}{l}\bar{m} \\
0 \\
0\end{array}$ & $\begin{array}{l}\hat{m} \\
\text { in }\end{array}$ & 100,00 & \multirow{4}{*}{$\begin{array}{l}\bar{\sigma} \\
\text { N } \\
\text { O } \\
\text { 1 }\end{array}$} \\
\hline 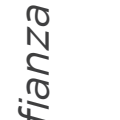 & & Peor & $\begin{array}{l}\hat{O} \\
\text { N } \\
M\end{array}$ & 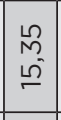 & \begin{tabular}{|l|}
$\infty$ \\
0 \\
$\nu$ \\
\end{tabular} & $\begin{array}{c}0 \\
\stackrel{0}{n} \\
\\
\end{array}$ & $\begin{array}{l}\infty \\
\stackrel{\infty}{ } \\
\stackrel{0}{\sim}\end{array}$ & $\mid$ & $\begin{array}{l}\infty \\
M \\
\omega\end{array}$ & 100,00 & \\
\hline ఏ & & Igual & 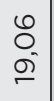 & $\begin{array}{l}\infty \\
0 \\
0 \\
0\end{array}$ & $\begin{array}{l}\infty \\
\infty \\
\infty\end{array}$ & 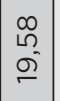 & $\begin{array}{l}\stackrel{\varphi}{\forall} \\
\stackrel{ \pm}{ \pm}\end{array}$ & $\begin{array}{l}\text { के } \\
\text { के }\end{array}$ & $\begin{array}{l}\infty \\
\infty \\
\infty \\
M\end{array}$ & 100,00 & \\
\hline$\stackrel{\Delta}{\Phi}$ & & Mejor & 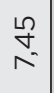 & $\begin{array}{c}\infty \\
\stackrel{\infty}{=}\end{array}$ & \begin{tabular}{|l|}
$\infty$ \\
$M$ \\
$\stackrel{N}{-}$ \\
\end{tabular} & 兄 & $\begin{array}{l}\stackrel{\leftrightarrow}{M} \\
\stackrel{\sim}{\sim}\end{array}$ & 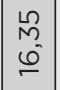 & 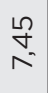 & 100,00 & \\
\hline$\frac{0}{0}$ & 중 & Total & $\begin{array}{l}\varrho \\
\varrho \\
\grave{i}\end{array}$ & 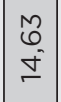 & $\begin{array}{l}\qquad \\
0 \\
6 \\
6\end{array}$ & $\begin{array}{l}\stackrel{2}{2} \\
0 \\
6 \\
\end{array}$ & 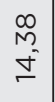 & $\mid \begin{array}{l}0 \\
+ \\
0 \\
0\end{array}$ & $\begin{array}{l}\text { N } \\
\text { Ln }\end{array}$ & 100,00 & \multirow{4}{*}{$\begin{array}{l}\bar{G} \\
N \\
N \\
0 \\
1\end{array}$} \\
\hline 包 & $\frac{0}{0}$ & Peor & $\underset{\substack{\infty \\
\sim}}{\sim}$ & $\begin{array}{l}\bar{n} \\
6 \\
6\end{array}$ & $\begin{array}{l}\bar{N} \\
\stackrel{n}{2}\end{array}$ & $\begin{array}{l}\dot{e} \\
M \\
M \\
\stackrel{m}{-}\end{array}$ & $\begin{array}{l}\circ \\
\circ \\
\stackrel{\sim}{-1}\end{array}$ & $\begin{array}{l}\bar{\sigma} \\
N\end{array}$ & $\begin{array}{l}N \\
M \\
\sigma\end{array}$ & 100,00 & \\
\hline $\begin{array}{l}0.5 \\
0 \\
0 \\
0\end{array}$ & $\frac{0}{2}$ & Igual & $\begin{array}{l}\stackrel{N}{M} \\
\stackrel{D}{D}\end{array}$ & $\begin{array}{l}\stackrel{\mathscr{n}}{\leftarrow} \\
\stackrel{n}{\leftarrow}\end{array}$ & $\begin{array}{l}\hat{x} \\
\infty \\
\infty\end{array}$ & 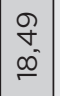 & 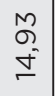 & $\begin{array}{c}N \\
N \\
\sigma\end{array}$ & $\begin{array}{l}\text { N } \\
\text { m }\end{array}$ & 100,00 & \\
\hline$\frac{0}{0} \underset{\infty}{\infty}$ & ষ্ণ & Mejor & \begin{tabular}{l}
$\infty$ \\
0 \\
0 \\
\hdashline
\end{tabular} & $\begin{array}{l}\text { ̊̊ } \\
\text { の่ }\end{array}$ & 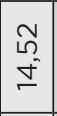 & $\frac{\infty}{\sigma}$ & $\begin{array}{l}\circ \\
\circ \\
\stackrel{-}{N} \\
\end{array}$ & $\begin{array}{l}\pi \\
\sigma^{-}\end{array}$ & $\begin{array}{l}N \\
M \\
\sigma\end{array}$ & 100,00 & \\
\hline 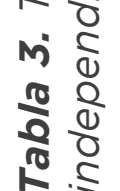 & $\begin{array}{c}\text { Variable } \\
\text { dependiente }\end{array}$ & $\begin{array}{l}\text { Procesos } \\
\text { electorales }\end{array}$ & $\begin{array}{l}\pi \\
0 \\
\pi \\
z\end{array}$ & V & $m$ & $\nabla$ & $n$ & 6 & $\begin{array}{l}\frac{0}{\mathfrak{U}} \\
\frac{1}{2}\end{array}$ & 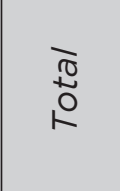 & $\begin{array}{l}\frac{5}{0} \\
\varepsilon \\
\frac{1}{0} \\
0 \\
0 \\
0\end{array}$ \\
\hline
\end{tabular}


La Tabla 4 presenta las respectivas estimaciones del modelo logit ordenado. A pesar de la intuición que surgió de las estadísticas descriptivas en las Tablas 2 y 3, las estimaciones revelan que los indicadores económicos (percepción de la economía personal y nacional) son irrelevantes para determinar la confianza en las elecciones y el Tribunal Electoral. En cambio, se confirma la relación causal entre la evaluación ciudadana del trabajo del presidente ( $\mathrm{H} 2)$ y la confianza hacia ambas instituciones. El coeficiente de esta variable es negativo y estadísticamente significativo a un $\mathrm{p}<0.001$ para las dos estimaciones. Este coeficiente se encuadra en la dirección esperada, por lo tanto, es menos probable que un ciudadano que considera que el trabajo del presidente es muy malo confíe en los procesos electorales y el Tribunal Electoral.

Por otra parte, cuando un ciudadano está de acuerdo en que "a los gobernantes les interesa lo que piense la gente" (eficacia externa), aumenta la probabilidad de confiar en dichas instituciones. Este coeficiente también goza de significación estadística $\mathrm{p}<0.001$ y de signo positivo. Respecto a la variable aprobación de la repostulación de Morales, los datos muestran que aquellos que la aprueban tiene más probabilidades de confiar en ambas instituciones. El coeficiente se ubica en la dirección esperada y es estadísticamente significativo a un $\mathrm{p}<0.001$ para las dos estimaciones. En cuando a la variable educación, ambas estimaciones contradicen la teoría, ya que mayores recursos educativos no generan más confianza institucional (Abrajano y Álvarez, 2010; Curvale, 2010).

En particular, en ambas estimaciones la variable Universidad es estadísticamente significativa a un nivel $\mathrm{p}<0.001$ y no se encuentra en la dirección esperada. Por 
ende, es menos probable que un ciudadano con estudios universitarios confíe en las elecciones y el Tribunal Electoral. Es interesante observar que, en el segundo modelo, la variable Primaria también es estadísticamente significativa a un $\mathrm{p}<0.001$. Esto sugiere que los ciudadanos con estudios básicos (primarios) tienen mayor probabilidad de confiar en el Tribunal Electoral. O, en otras palabras, si bien los más educados son desafectos y, quizá, hasta más críticos, en el sentido de Norris (2011), aquellos con escasos recursos educativos sí tenderán a confiar en estas instituciones.

Tabla 4. Estimación logit ordenada: aWlta confianza en las elecciones y el Tribunal Electoral

\begin{tabular}{|l|c|c|c|c|}
\hline \multirow{2}{*}{$\begin{array}{c}\text { Variables } \\
\text { independientes }\end{array}$} & \multicolumn{2}{|c|}{$\begin{array}{c}\text { Confianza en } \\
\text { los elecciones }\end{array}$} & $\begin{array}{c}\text { Confianza en } \\
\text { el Tribunal Electoral }\end{array}$ \\
\cline { 2 - 5 } Est. Coef & St. Error & Est. Coef & St. Error \\
\hline Edad & 0,032 & $(0,11)$ & $0,38^{* * *}$ & $(0,11)$ \\
\hline \multicolumn{5}{|c|}{ Educación } \\
\hline Ninguno & $-0,01^{*}$ & $(0,00)$ & $-0,02^{* * *}$ & $(0,00)$ \\
\hline Primaria & $-0,27$ & $(0,55)$ & 0,93 & $(0,54)$ \\
\hline Universidad & 0,10 & $(0,15)$ & $0,63^{* * *}$ & $(0,15)$ \\
\hline \multicolumn{5}{|c|}{ Indicadores económicos } \\
\hline $\begin{array}{l}\text { Peor percepción } \\
\text { económica } \\
\text { (personal) }\end{array}$ & $-0,15$ & $(0,09)$ & $-0,12$ & $\left(0,099^{* * *}\right.$ \\
\hline $\begin{array}{l}\text { Peor percepción } \\
\text { económica (país) }\end{array}$ & $-0,03$ & $(0,09)$ & $-0,15$ & $(0,09)$ \\
\hline $\begin{array}{l}\text { Muy mala evalua- } \\
\text { ción del trabajo } \\
\text { presidencial }\end{array}$ & $-0,66^{* * *}$ & $(0,07)$ & $-0,57^{* * *}$ & $(0,07)$ \\
\hline Eficacia externa & $0,38^{* * *}$ & $(0,03)$ & $0,28^{* * *}$ & $(0,03)$ \\
\hline
\end{tabular}




\begin{tabular}{|l|c|c|c|c|}
\hline \multirow{2}{*}{$\begin{array}{c}\text { Variables } \\
\text { independientes }\end{array}$} & \multicolumn{2}{|c|}{$\begin{array}{c}\text { Confianza en } \\
\text { los elecciones }\end{array}$} & \multicolumn{2}{c|}{$\begin{array}{c}\text { Confianza en } \\
\text { el Tribunal Electoral }\end{array}$} \\
\cline { 2 - 5 } & Est. Coef & St. Error & Est. Coef & St. Error \\
\hline $\begin{array}{l}\text { Aprobación } \\
\text { re-postulación }\end{array}$ & $0,79^{* * *}$ & $(0,13)$ & $0,66^{* * *}$ & $(0,13)$ \\
\hline N & 1.231 & & 1.224 & \\
\hline Log-Likelihood & \multicolumn{2}{|c|}{-2007.7018} & \multicolumn{2}{c|}{-2006.0696} \\
\hline
\end{tabular}

Nota: (a) la categoría base es Secundaria. ${ }^{*} p<0.05,{ }^{* *} p<0.01,{ }^{* * *} p<0.001$ Fuente: Elaboración propia, con datos de LAPOP (2019).

La edad de los encuestados también ayuda a explicar quién tiene más probabilidad de confiar. La variable edad es significativa a un nivel $\mathrm{p}<0.05$ para las elecciones y a un nivel $\mathrm{p}<0.001$ para el órgano electoral. El coeficiente de edad es negativo para las dos estimaciones (contrario a lo esperado). Esto sugiere que entre más edad tenga una persona menor probabilidad habrá de confiar en las instituciones electorales. Esto resulta interesante, pues varios estudios han subrayado que los jóvenes son los más desafectos, ya que no tienen interés en la política y la consideran corrupta (Abad y Trak, 2013). El género solamente es significativo para la estimación del órgano electoral y, acorde a lo esperado, su signo es negativo.

En resumen, nuestro modelo logit ordenado solo confirma la hipótesis 2. Esto resulta interesante, ya que, a pesar de la reducción de los precios de las materias primas y un clima económico no tan favorable, las variables económicas no marcan la diferencia. Sin embargo, al observar que la variable desempeño gubernamental sí es significativa a un nivel $\mathrm{p}<0.001$, también podemos concluir que los ciudadanos evalúan las elecciones y el órgano electoral en función de la gestión gubernamental, la cual está sujeta a la coyuntura nacional. Esto genera 


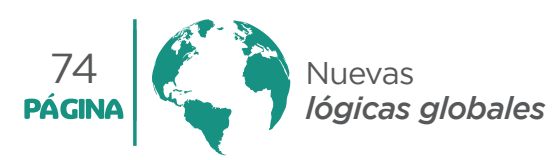

dudas sobre la capacidad del sistema para cimentar la confianza institucional y garantizar una adecuada responsivenness por parte de las autoridades electas. Por lo tanto, estos datos evidencian la politización de la confianza institucional y la omnipresencia de la figura de Morales en diversas arenas institucionales.

\section{Conclusiones}

La confianza institucional es esencial para las democracias representativas, ya que para los ciudadanos representa la posibilidad de relajar la necesidad de controlar y monitorear permanentemente la acción de los políticos. Para las instituciones, la confianza depositada en ellas se considera como una fuente de poder que aumenta la probabilidad de que sus decisiones serán aceptadas (Citrin y Muste, 1999). Según los datos de LAPOP (oleada 2018/2019), las democracias latinoamericanas producen instituciones políticas en las que la gente no confía, por ejemplo, centrando el análisis a nivel de países y tomando en cuenta a los procesos electorales, los datos revelan que Uruguay, Chile y Costa Rica son únicos países con "buenos" niveles de confianza, mientras que Honduras y República Dominicana se encuentran en el polo opuesto. Bolivia no se ubica en ningún extremo, sin embargo, es un interesante caso de estudio, ya que en 2019 vivió uno de los shocks políticos y sociales más graves de los últimos años: la destitución presidencial de Evo Morales.

Los principales hallazgos del modelo logit ordenado realizado para el caso boliviano son los siguientes: primero, la evaluación de la economía personal y nacional no influyen en la confianza hacia las dos instituciones analizadas; y segundo, el desempeño gubernamental de Morales marca la diferencia. Por lo tanto, un "peor" 
desempeño gubernamental reduce la probabilidad de confianza en ambas instituciones. Por otra parte, es interesante observar que determinados factores sociodemográficos, como el alto nivel educativo y la edad, también influyen en la probabilidad de confiar. Asimismo, tanto la eficacia externa como el haber aprobado la repostulación de Morales a las próximas elecciones fueron estadísticamente significativos. Esto evidencia que sentirse tomado en cuenta por los políticos y ser permisivo con la candidatura de Morales aumentan la probabilidad de confianza institucional.

En resumen, la idea central del análisis precedente es que en Bolivia la confianza institucional está fuertemente vinculada a la gestión del presidente. Esto contradice la mayor parte de la literatura sobre confianza (o desafección) institucional, que indica que es una actitud más estable a lo largo del tiempo y es difícil de modificar una vez que el individuo ha adquirido el "síndrome" (Norris, 1999). Por ello, pensar en la confianza política como una consecuencia de los resultados gubernamentales parecería evidenciar que no existe una separación clara entre los gobiernos de turno, el Estado y la autonomía institucional y política de los procesos electorales y su órgano regulador. Por último, esto sugiere que los juicios de confianza se alejan del ideal del ciudadano racional que evalúa las instituciones por su justo mérito (Bargsted y Torcal, 2015a).

Sin embargo, aun cuando puede observarse cierto grado de politización sobre la confianza, no debe perderse de vista que la interrelación entre percepción de la economía nacional y confianza institucional también puede dar cuenta de un proceso por el cual, a medida que la ciudadanía experimenta cambios favorables en sus niveles de ingreso - con todas las consecuencias asociadas, como 


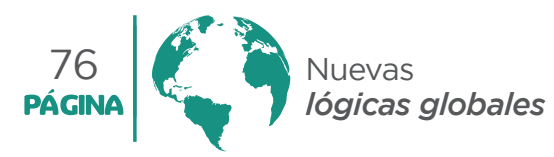

la reducción de la pobreza y aumentos en los niveles de escolaridad-podría estar emergiendo un ciudadano más educado y desvinculado de los lazos clientelistas, a la par que un ciudadano más crítico, en el sentido de Norris (1999), y que confía en las instituciones atendiendo cada vez más a su capacidad afectiva de resolver los problemas económicos y sociales que afectan al país. Tras este análisis, surgen también algunas interrogantes fundamentales que abren interesantes líneas de investigación: ¿cómo fomentar la confianza en estas instituciones en sociedades tan plurales y desafectas? ¿Qué medidas pueden aumentar la independencia de los órganos electorales: la autonomía presupuestaria o los nombramientos sin la intervención de los poderes estatales?

\section{Referencias}

Abad, A., y Trak, J. (2013). Desafección política en Bolivia, Ecuador y Venezuela en 2010: un análisis comparado. Cuadernos del Cendes, 30(82). http://ve.scielo.org/scielo.php?script=sci_ arttext\&pid=S1012-25082013000100004

Abrajano, M., \& Álvarez, R. (2010). Assessing the Causes and Effects of Political Trust among U. S. Latinos. American Politics Research, 38(1), 110-141.

Alcántara, M. (2009). América Latina: la política inconclusa. Sistema, (208-209), 5-24.

Alcántara, M. (2012). El oficio de político. Madrid: Tecnos.

Almond, G. \& Verba, S. (1965). The Civic Culture. Boston: Little Brown and Company.

Anderson, C. D. (2009). Institutional change, economic conditions and confidence in government: Evidence from Belgium. Acta Política, 44(1), 28-49. 
Anderson, C. J., Blais, A., Bowler, S., Donovan, T., \& Listhaug, O. (2005). Losers' Consent: Elections and Democratic Legitimacy. New York: Oxford University Press.

Anduiza, E., y Bosch, A. (2012). Comportamiento político y electoral. Barcelona: Editorial Planeta, S. A.

Bargsted, M., y Torcal, M. (2015a). Explicando la confianza política: ¿economía o política? En L. Paramio (Ed.), Desafección política y gobernabilidad: el reto político (pp. 201-228). Madrid: Marcial Pons.

Bargsted, M. y Torcal, M. (2015b). Confianza política en Europa y América Latina: Estudio comparado con datos y causas. En L. Paramio (Ed.), Desafección política y gobernabilidad: el reto político (pp. 163200). Madrid: Marcial Pons.

Bargsted, M., Castillo, C., \& Somma, N. (2017). Political Trust in Latin America. En S. Zmerli y T. Van der Meer (Eds.) Handbook on political trust (pp. 395417). Northampton, Estados Unidos: Edward Elgar Publishing.

Barrientos, R. (2020). Bolivia, ocaso del proceso de cambio. Estudios de Política Exterior, (193). https:// www.politicaexterior.com/articulos/politicaexterior/bolivia-ocaso-del-proceso-cambio/

Basabe-Serrano, S. (2017). Las distintas caras del presidencialismo: debate conceptual y evidencia empírica en dieciocho países de América Latina. Revista Española de Investigaciones Sociológicas, (157), 3-22.

Bauman, Z., y Bordoni, C. (2016). Estado de crisis. Barcelona: Espasa Libros. 
Booth, J., y Seligson, M. (2009). The legitimacy puzzle in Latin America: Political support and democracy in eight nations. Cambridge University Press.

Brenes, D. (2009). (Des)confianza en los organismos y procesos electorales en América Latina. Élites parlamentarias Latinoamericanas. Boletín de opinión, 10(09). https://oir.org.es/pela/wp-content/ uploads/2019/05/BOLETIN_ANALISIS_10.pdf

Campello, D. (2015). The Politics of Market Discipline in Latin America: Globalization and Democracy. Cambridge: Cambridge University Press.

Castorena, O., Morton, B., y Pizzolitto, G. (2020). Capítulo 2: Legitimidad democrática en las Américas y en Ecuador. En P. Moncagatta, A. Moscoso, S. Pachano, D. Montalvi y E. Zechmeister (Eds.), Cultura política de la democracia en Ecuador y en las Américas, 2018/19: tomándole el pulso a la democracia (pp. 25-47). https://www.vanderbilt.edu/lapop/ ecuador/AB2018-19_Ecuador_Country_Report_ V2_W_02.03.20.pdf

Citrin, J., \& Muste, C. (1999). Trust in Government. In J. P. Robinson (ed.), Measures of Political Attitudes. San Diego: Academic Press.

Curvale, C. (2013). Citizen participation, social trust, and ethnic groups in Ecuador. Asian Journal of Latin American Studies, 26(1), 75-96.

Dahl, R. (1971). La Poliarquía. Madrid: Tecnos.

Flores, F. (2019, 13 de noviembre). Bolivia: incierta transición. Estudios de Política Exterior. https:// www.politicaexterior.com/latinoamerica-analisis/ bolivia-incierta-transicion/ 
Freidenberg, F. (2013). La calidad de las elecciones en América Latina. Mundo Electoral, 6(18). https:// www.researchgate.net/publication/264424522_La_ calidad_de_las_elecciones_en_America_Latina/stats

Hagopian, F., \& Mainwaring, S. (2005). The Third Wave of Democratization in Latin America: Advances and Setbacks. New York: Cambridge University Press.

Hardin, R. (2002). Trust and Trustworthiness. New York: Russell Sage Foundation.

IDEA Internacional. (2019). El estado de la democracia en el mundo y en las Américas 2019. Confrontar los desafíos, revivir la promesa. https://doi.org/10.31752/ idea.2019.32

Kucel, A. (2004). Political Disaffection in 3rd Wave Democracies in Europe. Barcelona: Universidad Pompeu Fabra.

Levitsky, S., \& Roberts, K. (2011). The Resurgence of the Latin American Left. Baltimore: The Johns Hopkins University Press.

Mainwaring, S. (2006). State deficiencies, party competition, and confidence in democratic representation in the Andes. En S. Mainwaring, A. M. Bejarano y E. Pizarro (Eds.), The Crisis of Democratic Representation in the Andes (pp. 295345). Stanford: Stanford University Press.

Mair, P. (2015). Gobernando el vacío: banalización de la democracia occidental. Madrid: Alianza Editorial.

Meer, T., \& Dekker, P. (2011). Trustworthy states, trusting citizens? A Multilevel Study into Objective and Subjective determinants of political trust. En S. Zmerli and M. Hooghe (Eds.), Political trust. Why context matters (pp. 95-166). Colchester, UK: ECPR Press. 


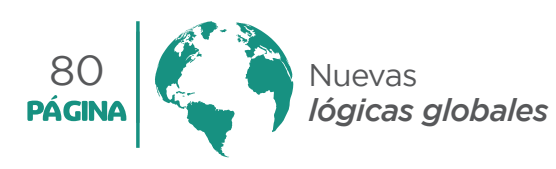

Mishler, W., y Rose, R. (2001, February). What are the origins of political trust? Comparative Political Studies, (33).

Montero, J., Gunther, R., y Torcal, M. (1998). Actitudes hacia la democracia en España: legitimidad, descontento y desafección. Reis, 83(98), 9-49.

Nohlen, D. (1995). Elecciones y sistemas electorales (pp. 31-57). Caracas: Nueva Sociedad.

Norris, P. (1999). Critical citizens: global support for democratic government. New York: Oxford University Press.

Norris, P. (2011). Democratic De cit. Critical Citizens Revisited. New York, Cambridge: University Press.

O’Donnell, G. (2007). Disonancias. Críticas democráticas a la democracia. Buenos Aires: Prometeo Libros.

Palazuelos, I. (2012). La desconfianza en los partidos políticos y la percepción ciudadana de desempeño gubernamental: México ante América Latina. Revista Mexicana de Análisis Político y Administración Pública, 1(1), 79-107.

Pasquino, G. (2014). Democracia, elecciones, partidos. En M. Bovero y V. Pazé (Eds.), La democracia en nueve lecciones (pp. 29-46). Madrid: Editorial Trotta.

Pharr, S. J., \& Putnam, R. (2000). Disaffected Democracies. What's Troubling the Trilateral Countries. Princeton: Princeton University Press.

Pogrebinschi, T. (2013). El giro pragmático de la democracia en América Latina. Nueva Sociedad, Friedrich Ebert Stiftung. http://library.fes.de/pdf-files/nuso/10084.pdf

Proyecto de Opinión Pública de América Latina (LAPOP). (2008). Bases de datos ronda 2008. http:// 
datasets.americasbarometer.org/database/index. php?freeUser=true\#

Proyecto de Opinión Pública de América Latina (LAPOP). (2012). Bases de datos ronda 2012. http:// datasets.americasbarometer.org/database/index. php?freeUser=true\#

Proyecto de Opinión Pública de América Latina (LAPOP). (2017). Bases de datos ronda 2016/2017. http:// datasets.americasbarometer.org/database/index. php?freeUser=true\#

Proyecto de Opinión Pública de América Latina (LAPOP). (2019). Bases de datos ronda 2018/2019. http:// datasets.americasbarometer.org/database/index. php?freeUser=true\#

Romero, S. (2016). Orientaciones, dilemas y desafíos de las reformas electorales en América Latina en el inicio del siglo XXI. En K. Casas-Zamora, M. Vidaurri, B. Muñoz-Pogossian y R. Chanto (Eds.), Reformas políticas en América Latina: tendencias y casos (pp. 93-133). Washington, D. C: Secretaría General de la Organización de los Estados Americanos.

Ross, A., \& Escobar-Lemmon, M. (2011). The price of personalizing politics: Political distrust and economic performance in Latin America, 1996-2006. Electoral Studies, 30(3), 406-416.

Schattschneider, E. E. (1942). Party Government. New York, Holt, Rinehart and Winston. (En español: Régimen de Partidos (1964). Madrid: Editorial Tecnos).

Schedler, A. (2002). Elections without democracy: The menu of manipulation. Journal of Democracy, 13(2), 36-50.

Stefanoni, P. (2019, octubre). ¿Qué pasa en Bolivia? Nueva Sociedad. Opinión. https://nuso.org/articulo/ Bolivia-Evo-Morales-Carlos-Mesa-elecciones/ 
Stefanoni, P. (2020, marzo). Las lecciones que nos deja Bolivia. Nueva Sociedad. Opinión. https://nuso.org/ articulo/Bolivia-Evo-Morales-elecciones/

Tanaka, M. (2015). Agencia y estructura, y el colapso de los sistemas de partidos en los países andinos. En M. Torcal (Ed.), Sistemas de partidos en América Latina (pp. 161-182). Madrid: Anthropos.

Torcal, M., \& Montero, J. R. (Eds.). (2006). Political disaffection in contemporary Democracies. Social Capital, Institutions, and Politics. London: Routledge.

Vallés, J. M., y Bosch, A. (1997). Sistemas electorales y gobierno representativo. Barcelona: Editorial Ariel.

Zovatto, D. (2018). El estado de las democracias en América Latina a casi cuatro décadas del inicio de la Tercera Ola Democrática. Revista de Derecho Electoral, 25, 7-27. https://www.tse.go.cr/revista/ art/25/zovatto_garetto.pdf 